Zbornik Instituta za kriminološka

i sociološka istraživanja

2021 / Vol. XL / 2-3 / 59-76

Pregledni naučni rad

Primljeno: 2. 6. 2021. godine

Prihvaćeno: 11. 10. 2021. godine

DOI: $10.47152 /$ ziksi202123024

UDK: 316.034:343.811

\title{
ZATVORSKA SOCIJALNA KLIMA* pojam, faktori i značaj zatvorske socijalne klime
}

Ljeposava Ilijić*

\begin{abstract}
Sve intenzivnije usmeravanje stručne naučne pažnje ka izučavanju zatvorske socijalne klime, poslednjih decenija, od izuzetne je važnosti, jer rezultati istraživanja ukazuju na podatak da karakteristike zatvora (fizičke, arhitektonske, socijalne, organizacione $i d r$.) zapravo posreduju između prestupnika i rehabilitacionih ili terapijskih mera. Drugim rečima, socijalna ili institucionalna klima potencijalno može da olakša uspešnu rehabilitacïu osuđenika ili pak, da ometa njen napredak. Pregledom literature uočljiv je veliki broj različitih terminoloških određenja i definisanja pojma zatvorske socijalne klime, pa se ona često definiše $i$ kao materijalna, socijalna $i$ emocionalna stanja date jedinice $i$ podrazumeva interakciju između navedenih faktora. Opšte konceptualizacije socijalne klime uključuju relacionu klimu, psihosocïjalno okruženje, socïalnu atmosferu, socïalno okruženje i atmosferu odeljenja. Socijalna klima se takođe može meriti procenom stvarne, poželjne $i$ očekivane socijalne klime $i$ kako je doživljavaju osuđenici, zaposleni stručni radnici u zatvoru ili pojedinci iz društvene zajednice. U ovom radu, autor nastoji da osvetli pojam zatuorske socijalne klime, kao i faktore koji je determinišu. Poseban naglasak u radu je stavljen na percepciju zatvorske socijalne klime od strane stručnih radnika, uticaju koji socijalna klima ostvaruje na ponašanje osuđenika, kao i sagledavanju svih onih aspekata koji
\end{abstract}

\footnotetext{
* Ovaj rad nastao je kao rezultat istraživačkog angažovanja prema Planu i programu rada Instituta za kriminološka i sociološka istraživanja za 2021. godinu.

*Naučni saradnik, Institut za kriminološka i sociološka istraživanja. E mail: lelalela_bgd@yahoo.com
} 


\author{
Zbormik IKSI, 2-3/2021 - Lj. Ilijić \\ „Zatvorska socijalna klima - pojam, faktori i značaj zatvorske socijalne klime”, (str. 59-76)
}

proizilaze iz radnog okruženja, vrste radne organizacije $i$ odnosa, a koji utiču na formiranje socijalne klime u zatvorskoj sredini.

\begin{abstract}
KLJUČNE REČI: zatvorska socijalna klima / zatvorsko okruženje / ponašanje osuđenika / uloga stručnih radnika
\end{abstract}

\title{
1. UVODNA RAZMATRANJA
}

\subsection{O pojmu zatvorske socijalne klime}

Brojne zemlje Severne Evrope $^{1}$, poslednjih decenija, pod uticajem evropskih institucija kao što su Savet Evrope i Evropska unija, pokazuju sve temeljniju posvećenost izgradnji humanog zatvorskog sistema, u kojem zatvori više neće biti izvor dodatne patnje i boli, već sistemi koji treba da doprinesu, koliko je to moguće, reintegraciji osuđenika u zajednicu (Snacken, 2010; Van Zyl Smit, \& Snacken, 2009). Jedan od možda najvažnijih aspekata humanog zatvorskog iskustva je održavanje sigurne i podsticajne zatvorske klime (Bosma, van Ginnken, Sentse, \& Palmen, 2020).

Uporedo sa sve intenzivnijom „humanizacijom“ zatvora, i ustručnoj literaturi sve je uočljiviji stav daje za uspešnu reintegraciju osuđenika u društvenu zajednicu i sprečavanje recidiva, potreban mnogo veći skup „alata” ili „okolnosti” od samog tretmana, a koji će omogućiti, između ostalog, da službenici tretmana prevaziđu puko odvraćanje u cilju postizanja reintegracije osuđenika i redukcije recidiva (Hall, \& Chong, 2018). Većina evaluacijskih istraživanja zatvorskih tretmana, uzimala je „zdravo za gotovo” pretpostavku da je „tretman“ ključna varijabla u postizanju i održavanju promena u ponašanju osuđenika (Lösel, 1995: 19), zanemarujući uticaj koji ostvaruju faktori iz zatvorskog okruženja i zatvorske socijalne klime na tretman. Naučni napredak u razumevanju društvenih odnosa koji važe u zatvorskoj zajednici, doveo je i do uvažavanja širih apekata socijalne i moralne klime u zatvorima i proučavanja njihovog uticaja na ishode primenjenih tretmana (Lösel, 1992, prema: Auty, \& Liebling, 2019).

Usmeravanje stručne pažnje ka izučavanju zatvorske socijalne klime je od izuzetne važnosti, jer stavovi naučnika potvrđuju da karakteristike zatvorske socijalne klimezapravo posreduju između prestupnika i rehabilitacionih ili terapijskih mera. Drugim rečima, socijalna ili institucionalna klima potencijalno može da olakša uspešnu rehabilitaciju osuđenika ili pak, da ometa njen napredak (Day, Casey, Vess, \& Huisy, 2011). Značaj merenja i razmatranja zatvorske klime je ključan za razumevanje onoga što se dešava u zatvoru, kao i onoga što se može očekivati nakon otpuštanja iz zatvora (Ross, Diamond, Liebling, \& Saylor, 2008).

\footnotetext{
${ }^{1}$ Prvenstveno Skandinavske zemlje, Danska, Norveška i Švedska.
} 


\section{Zbormik IKSI, 2-3/2021 - Lj. Ilijić \\ „Zatvorska socijalna klima - pojam, faktori i značaj zatvorske socijalne klime”, (str. 59-76)}

Uprkos velikoj teorijskoj zastupljenosti ideja o terapijskom institucionalnom okruženju i zatvorskoj kulturi (Beech \& Hamilton-Giachritsis, 2005; Waters \& Megathlin, 2002; Day et al., 2011), socijalnoj klimi (Tonkin, 2015; Schalast, Redies, Collins, Stacey, \& Howells, 2008), socijalnom miljeu (Day et al., 2011), zatvorskoj klimi (Ross et al., 2008) i moralnoj klimi (Liebling, 2011), pokazalo se da je teško definisati i operacionalizovati šta se podrazumeva pod ovim pojmovima u stručnoj literaturi. Različite konceptualizacije dovele su do razvoja različitih specifikacija u razmerama i dimenzijama za merenje socijalne klime. Većina instrumenata za procenu socijalne klime razvijena su u vezi sa određenim postavkama / osobinama lečenja (tretmana), karakteristikama / vrsti klijenata (Tonkin, 2015) i vrsti ustanove, a univerzalne metode za pouzdano merenje socijalne klime zatvorskih ustanova ne postoje (Day et al., 2011), već se postojeći instrumenti ${ }^{2}$ prilagođavaju karakteristikama ustanove i specifičnostima populacije. Uočavamo da je, socijalna klima koncipirana i precizirana na mnogo različitih načina, koji se oslanjaju na opšte i na specifične koncepte. Opšte konceptualizacije socijalne klime uključuju relacionu klimu, psihosocijalno okruženje, socijalnu atmosferu, socijalno okruženje i atmosferu zatvorskog odeljenja (Brunt \& Rask, 2012; Moos, 1974; Tonkin, 2015). Socijalna klima se takođe može meriti procenom stvarne, poželjne i očekivane socijalne klime inačina na koji je doživljavaju osuđenici, zaposleni stručni radnici u zatvoru ili pojedinci iz društvene zajednice (Moos, 2003). Bez obzira na terminološku neujednačenost, postoji opšte priznanje da zatvori imaju određeni „karakter” (Moos, 1975), koji utiče na dobrobit i ponašanje osuđenika tokom i nakon izvršenja zatvorske kazne (Boone, Althoff, \& Koenraadt, 2016).

Pregledom literature uočavamo veliki broj različitih terminoloških određenja 3 i definisanja pojma zatvorske socijalne klime, pa se ona često definiše i ka omaterijalna, socijalna i emocionalna stanja date jedinice i podrazumeva interakciju između faktora (Moos, 1989) ili kao „skup svojstava ili uslova koji se odnose na klimu unutrašnjeg okruženja, njenu organizaciju, onako kako je percipiraju njeni članovi“ (Ajdukovic, 1990: 422). Često se u literaturi koristi i sinonimno sa terminima „zatvorsko okruženje“ (Ross et al., 2008: 4) i zatvorska socijalna klima.

Dakle, socijalna klima, kao multidimenzionalni konstrukt (Auty \& Liebling, 2019) se sastoji od različitih komponenti koje opisuju kako (na koji način) osoblje ili osuđenici doživljavaju određenu (zatvorsku) jedinicu. Ove komponente sadrže niz karakteristika, koje uključuju (ali se ne ograničavaju samo na to) npr. koliko su osuđenici i osoblje bezbedni od pretnji agresijom i nasiljem (od strane drugih osuđenika), koliko je prisutna podržavajuća terapijska usmerenost, u kojoj meri su zadovoljene fizičke / psihološke potrebe osuđenika, i u kojoj meri se vidi da sredina

\footnotetext{
${ }^{2}$ Neke od često upotrebljavanih skala za merenja socijalne klime su CIES (Correctional Institutions Environment Scale) / WAS (Ward Atmosphere Scale), EssenCES, MQPL (Measuring the Quality of Prison Life).

3 Brunt i Rask (2005) ispitivali su ono što su nazvali „psihosocijalnom atmosferom“ odeljenja, dok su Ross i saradnici (2008) proučavali „zatvorsko okruženje“, povezujući ga sa nivoima zadovoljstva i osuđenika i osoblja. Ostali izrazi koji se koriste u kriminološkim istraživanjima, uključuju pojmove „socijalnog okruženja“(Smith et al., 1997), „klimatsku percepciju“ (Parker et al., 2003) i sl.
} 
(zatvorska) pruža priliku za učenje novih veština i usvajanje prosocijalnog ponašanja (Tonkin, 2015; Schalast et al.,2008).

Boone i saradnici (Boone et al., 2016) identifikuju šest primarnih domena zatvorske socijalne klime, koju čine: odnosi u zatvoru, bezbednost i red, kontakt sa spoljašnjim svetom, zatvorski objekti, postojanje smislenih / svrsishodnih aktivnosti i autonomija. Neki od ovih domena zatvorske socijalne klime povezani su, ne samo sa prirodom ljudskih odnosa u zatvoru, kako sa osobljem, tako i sa drugim osuđenicima, već i sa sposobnošću održavanja odnosa / kontakata sa pojedincima i porodicom izvan zatvora. Ostali domeni zatvorske socijalne klime povezani su sa konkretnim fizičkim uslovima života u zatvoru (pri čemu se prvenstveno misli na kvalitet i veličinu zatvorskih objekata, uslove smeštaja u ćelijama, kvalitet hrane i sl.) i aktivnostima dostupnim u zatvoru (kao što su sportske i rekreativne aktivnosti, dostupnost biblioteke i sl.), pravilima koja regulišu ponašanje i obimom do kojeg osuđenici imaju određenu slobodu da samostalno donose odluke i kreću se po zatvoru (autonomija). Pored toga, arhitektonske karakteristike zgrade, stručno osoblje i sastav zatvoreničke populacije smatraju se važnim faktorima koji stvaraju okolnosti neophodne za pozitivno životno okruženje (Boone et al., 2016).

Značaj socijalne klime naglašen je u brojnim studijama, koje su ukazale na empirijski odnos između socijalne klime i važnih kliničkih / organizacionih ishoda u kazneno-popravnim i psihijatrijskim ustanovama. Tako je na primer utvrđeno da je pozitivna socijalna klima povezana sa većim stepenom zadovoljstva stručnih radnika i osuđenika, a to zadovoljstvo uključuje zadovoljstvo kvalitetom interakcije između osoblja i osuđenika, zadovoljstvo kvalitetom ponuđenih rehabilitacionih aktivnosti i tretmana i zadovoljstvo zbog toga što je ustanova sigurno mesto za život i rad (Bressington, Stewart, Beer, \& MacInnes, 2011).

Ovaj rad predstavlja pokušaj osvetljavanja uloge i značaja koji socijalna klima ima na sprovođenje i krajnji ishod primenjenih programa tretmana u zatvoru. Čini se da postoji značajne terapijske mogućnosti koje nastaju upravo kroz pažljivo identifikovanje društvenog funkcionisanja i kvaliteta interakcije između stručnog osoblja, osuđenika i institucije. U ovom radu, autor takođe nastoji na prikaže faktore koji determinišu zatvorsku socijalnu klimu, kao i načine na koje socijalna klima determiniše ponašanje stručnog osoblja i osuđenika. Zatvorska socijalna klima jedan je od nekoliko ekoloških faktora na listi institucionalnih korelata, koji se često zanemaruju $\mathrm{u}$ istraživanjima, a koji bi mogli objasniti značajne razlike $\mathrm{u}$ ishodim primenjenih programa tretmana (Attar-Schwartz, 2017). Jasnija slika važnih aspekata zatvorske socijalne klime mogla bi unaprediti postojeće znanje o tome „šta daje rezultate“, čime bi se poboljšala efikasnost zatvorske kazne. 


\section{ZATVORSKA SOCIJALNA KLIMA KAO DETERMINANTA PONAŠANJA ZATVORSKOG OSOBLJA I OSUĐENIKA4}

Rezultati brojnih istraživanja navode uticaj koji zatvorska socijalna klima ima na krajnji ishod rehabilitacionog tretmana osuđenika (Ortmann, 2000; Hall \& Chong, 2018), odnosno, potvrđuju da zatvorska klima, životna sredina, socijalna i lična, može imati glavni efekat na recidiv, bilo samostalno, bilo u interakciji sa merama rehabilitacije kao što su terapija, obuka i obrazovanje i modeliranje odgovarajućih normi ponašanja od strane osoblja i drugih zatvorenika (Ross et al., 2008: 2). Takođe, pojedini autori navode da institucionalno okruženje ili socijalna klima mogu uticati i na druge aspekte zatvorskog života (Day et al., 2011), i determinisati ponašanje stručnog osoblja i osuđenika u zatvoru.

Tako se na primer, u literaturi mogu naći rezultati istraživanja koji sugerišu da su percepcije zatvorskog osoblja o zatvorskoj klimi u značajnoj korelaciji sa spremnošću osoblja za upotrebu sile prema osuđenicima. Istražujući prediktore upotrebe sile, Griffin (1999) je otkrio da određeni promenljivi aspekti zatvorske klime, kao što su: percipirani autoritet za vršenje kontrole nad osuđenicima, strah od viktimizacije od strane osuđenika, i kvalitet nadzora između zatvorskih službenika i njihovih supervizora, imaju veliki uticaj na upotrebu sile prema osuđenicima. Ukoliko službenici obezbeđenja percipiraju sopstveni autoritet kao visok, utoliko su manje spremni da upotrebe silu prema osuđenicima (Griffin, 1999).

U sistematskom pregledu koji su sproveli Gadon, Johnston i Cooke (2006), navodi se da se na osnovu pojedinih karakteristika, kao što su: struktura zatvora (stepen nadzora, nivo bezbednosti, veličina zatvora), struktura osuđenika (vrsta krivičnog dela, dužina izrečene kazne i sl.), osobine osoblja (dužina zaposlenja i broj godina iskustva), određene karaktersitike zatvorske ustanove (kao što je recimo prostorno i arhitektonsko uređenje), i osobine zatuorske uprave(način upravljanja zatvorom i sl.), može predvideti i učestalost nasilja u zatvoru. Važan podatak koji su dobili navedeni autori, odnosi se i na zaključak da osuđenici koji su pohađali programe obrazovanja, stručnog osposobljavanja i obuke za rad u industrijskom sektoru, imali niže stope disciplinskih prestupa i manji broj fizičkih napada na osoblje (Gadon, Johnston, \& Cooke, 2006). Ključ „uspeha” obrazovnih tretmana je delom sadržan i u tome što obrazovanje može delovati kao utočište koje poseduje drugačiju „emocionalnu klimu“ od one koja preovlađuje u široj zatvorskoj zajednici (Crewe, Warr, Bennett, \& Smith, 2013). Pored toga, istraživanje ukazuje na to da obrazovne aktivnosti doprinose oslobađanju od „dosade” zatvorskog života (Hughes, 2009), pomažu osuđenicima da se lakše nose sa deprivacijama (Maruna, 2010), pružaju prostor za prosocijalno modeliranje, uzajamnu podršku (Casey, Day, Vess, \& Ward, 2013) i pozitivnu socijalizaciju (Waller, 2000).

4 Nažalost, sveobuhvatna istraživanja zatvorske socijalne klime u zatvorima na našim prostorima nisu do sada rađena, tako da rad ostaje uskraćen za prikaz rezultata i analizu zatvorske socijalne klime u Srbiji. 


\section{Zbormik IKSI, 2-3/2021 - Lj. Ilijić \\ „Zatvorska socijalna klima - pojam, faktori i značaj zatvorske socijalne klime”, (str. 59-76)}

Značaj zatvorskog okruženja i zatvorske arhitekture čini se mnogo važnijim i uticajnijim faktorom ponašanja osuđenika i zatvorskog osoblja, nego što se to izgleda na prvi pogled. Kao što navodi Yewkes (2018), u zatvorsku arhitekturu i unutrašnju organizaciju zatvora, utkan je poseban filozofski stav o kazni i njenoj percepciji od strane društva, u datom vremenu. Dizajn zatvora, može potencijalno uticati na stavove, i posredno, na ponašanje zatvorskog osoblja i osuđenika. Estetska arhitektonska rešenja u zatvoru, kao što su ćelije koje su poput kaveza i fiksnog nameštaja, pričvršćenog zavrtnjima za pod, nosi potencijalnu poruku osuđenicima da su oni vandali i da društvo nema poverenja u njih. Neuništiv i neudoban nameštaj ne samo da uništava dostojanstvo osuđenika, već može odrediti i određene vrste identiteta i ponašanja (Yewkes, 2018). Stoga, nije diskutabilno da zatvori treba da nastoje da poboljšaju svoje kapacitete za uspešno sprovođenje programa tretmana $\mathrm{i}$ rehabilitacije stvaranjem pozitivne socijalne klime $\mathrm{u}$ zatvoru $\mathrm{i}$ uspostavljenjem arhitektonskih nacrta koji estetski ulivaju nadu kako osuđenicima, tako i stručnom osoblju. Dakle, programi rehabilitacije poput obrazovnih inicijativa, mogu se efikasnije sprovesti u prijatnijem zatvorskom okruženju, čime bi se umanjili negativni uticaji života $\mathrm{u}$ zatvoru, poboljšali izgledi za efikasnu socijalnu reintegraciju, ali i poboljšalo samopoštovanje osuđenika i njihov moral (Allen, 2017).

Bez obzira što se zatvorske ustanove suočavaju sa ograničenim materijalnim i budžetskim resursima, to ne umanjuje postojanje potrebe da zatvorske službe razmotre sprovođenje promenakako na društvenom-makro nivou, tako i na nivou arhitektonskog dizajna zatvora, kako bi maksimizovale svoje kapacitete za rehabilitaciju i poboljšale responzivnost osuđenika. U tom cilju, od koristi bi bila veća upotreba terapijskih alata $\mathrm{u}$ obliku programa motivacionih promena koji su usmereni na zadovoljavanje potreba i razvijanje pozitivnih kapacitetaosuđenika, posebno onih sa niskim nivoom rizika za recidivizam, ali koji takođe mogu dopuniti druge postojeće programe koji se pružaju prestupnicima sa srednjim i visokim rizikom za recidiv (Hall \& Chong, 2018).

Takođe, od velike pomoći može biti i usvajanje pristupa koji pospešuje inkluzivnost i različitost kako u smislu razvoja programa i aktivnosti koje se nude osuđenicima, tako i u pogledu pristupa grupama osuđenika uz poštovanje njihovih ličnih, penoloških i kriminoloških karakteristika i potreba. Aktivnosti koje mogu da poboljšaju socijalnu klimu u zatvoru, ne odnose se samo na aktivnosti i programe koji pružaju razvoj novih veština, obuku za određena zanimanja ili usvajanje novih znanja, već i na one koji mogu da poboljšaju ličnu samopercepciju i sposobnost snalaženja, prilagođavanja i napredovanja u zatvoru, kao i u zajednici nakon otpuštanja, poboljšavajući time mogućnosti za uspešnu reintegraciju u društvo. Kao što navode Hall i Chong (2018) zadatak promene zatvorske socijalne klime više je povezan sa ciljevima rehabilitacije i reintegracije nego odvraćanja ili odmazde.

Istraživanja ukazuju da skladna, pozitivna zatvorska klima podstiče i jača: socijalnu koheziju i uzajmno podržavanje među osuđenicima, održavanje međusobne podrške stručnih radnika i jača lična interesovanja za napore u cilju podsticanja pozitivnih promena u ponašanju kod osuđenika, iskustvenu sigurnost i spremnost za aktivnije uključivanje u programe rehabilitacije (Day et al., 2011). Konačno, pokazalo se da sprovođenje tretmana u okruženju koje ima pozitivnu socijalnu klimu povećava 


\section{Zbormik IKSI, 2-3/2021 - Lj. Ilijić \\ „Zatvorska socijalna klima - pojam, faktori i značaj zatvorske socijalne klime”, (str. 59-76)}

unutrašnju spremnost i motivaciju za angažovanje ka rehabilitacionim naporima osuđenika, kao i da jača perceptivnu terapijsku snagu uzajamnog odnosa rezidentterapeut (Beazley \& Gudjonsson, 2011; Day et al., 2011; Long et al., 2011; van der Helm, Beunk, Stams, \& van der Laan, 2014). Stoga nisu iznenađujući nalazi da je pozitivna socijalna klima u korelaciji sa većim stepenom postignutih pozitivnih promena u ponašanju osuđenika u zatvoru, kao i dužim trajanjem perioda bez novih krivičnih dela, nakon otpuštanja iz zatvora (Moos, 1975; Schubert, Mulvey, Loughran, \& Loyosa, 2012).

S druge strane, negativna socijalna klima povezana je sa većom učestalošću verbalne i fizičke agresije usmerene ka sebi, drugim osuđenicima ili stručnim radnicima, predmetima, kao i sa češćim epizodama povučenosti (Long et al., 2011; Ros, van der Helm, Wissink, Stams, \& Schaftenaar, 2013).

Morgan, u kontekstu rasprave o samopovređivanju i samoubistvu osuđenika $\mathrm{u}$ zatvorima tvrdi da „kvalitet života u zatvoru u velikoj meri zavisi od prirode odnosa između osuđenika i zatvorskih službenika“ (Morgan, 1994: 224). Pojedini autori ističu neophodnost da zatvorski režim, zatvorska kultura i atmosfera treba da budu što više fokusirani ka prevenciji samoubistava, ulaganjem dodatnih napora ka intervencijama za „ranjive“ zatvorenike (Day et al., 2011). U tom cilju, Morgan, na primer, predlaže da je ono što se zahteva „socijalna“, a ne „situaciona“ strategija, te da bi se umanjila verovatnoća (...) samoubistva (...) ne treba potencirati segregaciju, tehnološki nadzor i sl., već da treba razvijati (...) „dinamičnu sigurnost” - osmisliti aktivne režime u kojima će zatvorski službenici moći kroz humanizovane i svrsishodneaktivnosti pozitivno delovati na zatvorenike“ (Morgan, 1994: 224). Pojedini autori navode da bolje postupanje osoblja prema osuđenicima dovodi do većeg blagostanja osuđenika, manje stope discpilinskih prestupa i niže stope samoubistava (Liebling, 2011: 530), odnosno, postojanje visokog nivoa zabrinutosti (napetosti) je u visokoj korelaciji sa stopama samoubistva, koje se mogu objasniti značajnim razlikama u nivoima poštovanja, pravičnosti i humanosti koju osoblje pokazuje zatvorenicima (Liebling, 2011: 533). Stoga, moralna klima u zatvoru utiče na mogućnosti za opstanak, promene i rast (Auty \& Liebling, 2019).

Zatvorska socijalna klima reflektuje se i na stepen (ne)poštovanja reda i discipline (Day et al., 2011). Cooke (1992) tako identifikuje četiri elementa socijalne klime koji su važni prediktori institucionalnih incidenata, a to su: komunikacija između osoblja i zatvorenika, obuka osoblja, iskustvo osoblja i moral osoblja. Steinke (1991) je takođe otkrila da situacioni faktori u zatvorskom okruženju predviđaju agresivno ponašanje osuđenika koje može biti usmereno ka sebi (autoagresija), osoblju ili drugim osuđenicima.

Ponašanje zatvorskog osoblja utiče na percepciju zatvorskog života osuđenika (Garland, 1990; Auty \& Liebling, 2019). Istraživanja pokazuju da su stilovi postupanja koje upotrebljava osoblje direktno povezani sa percepcijom zatvorskih uslova života osuđenika (Molleman \& Leeuv, 2012). Brojni istraživači navode značaj koji ponašanje stručnog osoblja ima na percepciju socijalne klime od strane osuđenika (Molleman \& van der Broek, 2014), a Garland (1990) ističe da su zaposleni u zatvorima glavni nosioci zatvorske socijalne klime. 


\section{Zbormik IKSI, 2-3/2021 - Lj. Ilijić \\ „Zatvorska socijalna klima - pojam, faktori i značaj zatvorske socijalne klime”, (str. 59-76)}

Jedan od načina da se poboljša zatvorska socijalna klima jeste traganje za faktorima koji su promenljivi (od strane uprave) i koji su povezani sa osuđeničkom percepcijom zatvorskih uslova, kao što je postupanje sa osuđenicima. Ali da li to znači da bi se osoblje trebalo koncentrisati na životne uslove ili kontrolu? Da li treba da imaju za cilj prvenstveno bezbednost ili tretman? U literaturi se navedena dilema postavlja u okvire dva suprotna sistema vrednosti: harmonije i vrednosti bezbednosti (Liebling \& Arnold, 2004). Vrednosti harmonije uključuju poštovanje, poverenje i podršku konstruktivnim odnosima između osuđenika i osoblja, važnosti ličnog razvoja osuđenika i njihovog kontakta sa voljenim osobama. Vrednost bezbednosti odnosi se na primenu pravila i propisa, upotrebu autoritativnih akcija i prisile, upravljanje rizikom, rutinske aktivnosti i predvidivost (Molleman \& van der Broek, 2014).

Ukoliko je u zatvoru naglasak stavljen prvenstveno na održavanju reda i bezbednosti (što je posebno izraženo u zatvorima stogo zatvorenog tipa), uspostavljanje i održavanje vrednosti harmonije je izuzetno teško. Čini se da odgovor na prethodnu dilemu leži u traganju ka neophodnoj ravnoteži koja sa jedne strane garantuje bezbednost, a sa druge, omogućava osuđenicima dovoljno prostora da mogu da iskažu i svoju odgovornost u procesu tretmana (Molleman \& van der Broek, 2014).

Čini se da ne treba posebno naglašavati dau uslovima ozbiljne prekobrojnosti zatvorske populacije i strogih budžetskih ograničenja, održavanje bezbednog i podsticajnog zatvorskog okruženja predstavlja pravi izazov za stručne radnike u zatvoru (Bosma et al., 2020). Zatvori su složeni društveni sistemi u kojima borave ljudi različitog psihološkog, socijalnog i kulturnog porekla i koji komuniciraju u veoma ograničenom i restriktivnom okruženju (Wenk \& Moos, 1972) koje se smatra stresnim (Maschi, Viola, Morgen, \& Koskinen, 2015). Pored toga, zatvorskim pravilima, koja su restriktivne prirode, zabranjuju se i sankcionišu ponašanja koja bi se u nekim drugim, vanzatvorskim okolnostima smatrala legalnim i prihvatljivim (Camp, Gaes, Langan, \& Saylor, 2003). A kako se odstupanje od bilo kog pravila koje reguliše ponašanje u zatvoru smatra lošim ponašanjem (Eichenthal \& Jacobs, 1991; Irwin, 2005), funkcionisanje u ovom kontekstu može biti teško, posebno za populaciju koja u prošlosti imale poteškoća u pridržavanju i poštovanju društvenih pravila i normi ponašanja. Veliki broj studija je sledstveno naglasio važnost zatvorske klime u odnosu na prilagođavanje osuđenika na zatvaranje, ali i uticaj koji zatvorska klima ima na učestalost fizičkih i verbalnih incidenata (Bottoms, 1999; Camp et al., 2003; Wright, 1991) ili posedovanja i krijumčarenja nedozvoljenih predmeta i stvari (Reisig \& Mesko, 2009).

Manji broj naučnih studija proučavao je uticaj koji na nedolično ponašanje osuđenika ostvaruju faktori socijalne depriviranosti, u okviru kojih su analizirani odnosi između osoblja i osuđenika i učestalost poseta (Bosma et al., 2020). Osuđenici koji su izjavljivali da se stručno osoblje odnosi prema njima $\mathrm{s}$ poštovanjem, imali su manji broj disciplinskih prestupa i ređe su učestvovali u nedoličnom ponašanju (Beijersbergen, Dirkzvager, Eichelsheim, Van der Laan, \& Nieuvbeerta, 2015). Utvrđeno je i da pozitivna komunikacija sa zatvorskim čuvarima smanjuje učestalost (nasilnih) prekršaja osuđenika u zatvoru (Harer \& 


\author{
Zbormik IKSI, 2-3/2021 - Lj. Ilijić \\ „Zatvorska socijalna klima - pojam, faktori i značaj zatvorske socijalne klime”, (str. 59-76)
}

Steffensmeier, 1996), a osuđenici koji su redovno primali posete, uglavnom su imali manje disciplinskih prestupa (Jiang \& Winfree, 2006; Lahm, 2008).

\title{
3. ORGANIZACIJA RADA U ZATVORU, ZATVORSKI USLOVI I ZATVORSKA SOCIJALNA KLIMA IZ PERSPEKTIVE STRUČNIH RADNIKA
}

Pojedini autori naglašavaju nužnost šireg pristupa u proučavanju zatvorske socijalne klime, koji obuhvata proučavanje socijalne klime s aspekata organizacionih nauka i upravljanja ljudskim resursima (Molleman \& van der Broek, 2014). Obrazloženje za potrebe ovog pristupa leži u nastojanju da se pronađu faktori koji, ne samo da utiču na percepciju osuđenika o zatvorskim uslovima, već koji otkrivaju i uticaj koji ima organizacija rada u zatvoru na percepciju socijalne klime od strane zaposlenih i osuđenika. Stoga Molleman i van der Broek sugerišu na neophodnost detaljnijeg ispitivanja povezanosti i uticaja koji ostvaruje vrsta i način organizacije rada $\mathrm{u}$ ustanovi na stilove postupanja zaposlenih i percepciju zatvorskih uslova (Molleman \& van der Broek, 2014).

Treba imati na umu da brojni organizacioni postupci života i rada u zatvoru utiču na formiranje socijalne klime. Na primer, literatura o radu i organizacionoj psihologiji rada naglašava da su percepcije socijalne klime zaposlenih, povezane sa njihovim radnim ishodima kao što su produktivnost, radni učinak i stres na poslu. Studije su pokazale da negativna percepcija osoblja o klimi na radnom mestu značajno korelira sa negativnim stavovima zaposlenih (npr. namera napuštanja posla), nivoom zadovoljstva poslom (Ulrich, O'Donnell, Taylor, Farrar, Danis, \& Grady, 2007), psihološkim blagostanjem (Garrett \& McDaniel, 2001), stresom i izgaranjem (Griffin, Hogan, Lambert, Tucker-Gail, \& Baker, 2010), te motivacijom i poslovnim performansama (Parker, Beltes, Young, Huff, \& Altmann, 2003).

Veza između socijalne klime i učestalosti odsustva osoblja sa posla dokumentovana je brojnim istraživanjima (Day et al., 2011). Sistematskim pregledom literature Michie i Williams (2003) utvrdili su da su aspekti socijalne klime, poput prekovremenog rada, preopterećenja radom i pritisaka, nedostatka kontrole nad radom, nedostatka učešća u donošenju odluka, slabe socijalne podrške i nejasnog upravljanja radnom ulogom, povezani sa učestalom bolešću osoblja i njihovim češćim odsustvom sa posla. Drugim rečima, zaposleni koji rade u „napetoj i prejudiciranoj“ socijalnoj klimi u većem su riziku za pojavu negativnih simptoma koji proizilaze iz radnog okruženja i češće odsutnosti zbog bolesti, u poređenju s zaposlenima koji rade u opuštenoj i podržavajućoj klimi (Piirainen,Räsänen, \& Kivimäki, 2003: 180).

Negativna percepcija radnog okruženja npr. percipirana opasnost na radu, povezana je sa nižim radnim učinkom, učestalijim odsustvovanjima s posla i prisustvom namere da se napusti posao (Dowden \& Tellier, 2004), dok pozitivna percepcija radnog okruženja, poput podržavajuće psihosocijalne klime, proaktivnog stila upravljanja, konsenzusa ciljeva među osobljem, visokog stepena širine odlučivanja i 


\section{Zbormik IKSI, 2-3/2021 - Lj. Ilijić \\ „Zatvorska socijalna klima - pojam, faktori i značaj zatvorske socijalne klime”, (str. 59-76)}

zadovoljstvo radnim učinkom, povezanaje sa produktivnijim radnim učinkom i nižim stopama odsustvovanja zaposlenih (Härenstam, Palm, \& Theorell, 1988).

Jedan od opsežnijih pristupa razmatra socijalnu klimu organizacije kao neophodan „resurs za posao” (Day et al., 2011). Tako pojedini autori ovaj „resurs za posao” definišu kao ličnu sposobnost ublažavanja efekata stresa koji prističe iz uslova i prirode posla koji se obavlja (Waters, 1999).

Pored stilova rukovođenja zatvorom kao sistemom, na zatvorske uslove mogu uticati i drugi faktori koji potiču od strane stručnog osoblja (Day et al., 2011). Stručno osoblje, ukoliko je nezadovoljno radnim zadacima i radnom situacijom uglavnom ne doprinose ciljevima zatvorskog sistema (Cheeseman, Kim, Lambert, \& Hogan, 2011), odnosno, ne obezbeđuju vrednost bezbednosti, dostojanstvenog postupanja sa osuđenicima i adekvatnu rehabilitaciju. Stoga, interpersonalni kontakt i saradnja, kao i međusobna podrška u socijalno i psihološki teškim situacijama, moraju biti na zavidnom niovu kako bi se napravile pravilne procene i postigao pravi izbor aktivnosti tokom rada sa osuđenicima.

Kao što je već prethodno napomenuto, zatvorski sistemi koji nastoje da osiguraju bezbedne i humane uslove i postupanje koja ne ugrožava dostojanstvo osuđenika, postižu uspeh ne samo u uspešnoj resocijalizaciji osuđenika, već i pozitivne ishode $u$ pogledu smanjivanja rizika od nasilja i postupaka kojima se ugrožava red i disciplina u zatvoru. Specter (2006) navodi da su zatvorski uslovi i nasilje u zatvoru usko povezani. Zastarele i nehigijenske ustanove, nedostatak odgovarajuce zdravstvene zaštite ili nasvrsishodne aktivnosti mogu stvoriti okolnosti koje podstiču narušavanje discipline i nasilje u zatvoru. Boin i Rattray (2004) navode da su potrebna dva uslova da bi došlo do eskalacije nereda i nediscipline. Prvo, ako zatvorski rukovodioci i osoblje imaju različita stanovišta(npr. po pitanju primene određenih mera ili aktivnosti), što ugrožava njihovu sposobnost predviđanja i sprečavanja nasilja, i drugo, razvoj nefunkcionalnih obrazaca interakcije između osuđenika i osoblja može podstaći osuđenike da vrše (kolektivno) nasilje. Čak i mali događaj, kao što je promena menija, neočekivano zatvaranje ili otkazivanje programa tretmana u poslednjem trenutku, može lako poremetiti ravnotežu koja postoji između osoblja i osuđenika i stvoriti šansu za sukob (Boin \& Rattray, 2004).

Sledeći važan faktor koji određuje zatvorske uslove prističe iz samog režima izvršenja zatvorske kazne. Svakako, zatvorski uslovi i zatvorska socijalna klima variraju u zavisnosti od vrste zatvorske ustanove (stepen obezbeđenja) kao i tip odeljenja u zatvorskoj ustanovi. Takođe arhitektonska struktura zatvora smatra se važnom za percepciju uslova u zatvorima (Johnston, 2000), uz postojanje razlika između zatvora različitih kapaciteta, pojedinih krila (tipa odeljenja) zatvorskih paviljona, višespratnih jedinica, onih koji imaju velika i uređena dvorišta, spram onih zatvora u kojima su zelene površine male, paviljonskih ustanova i sl. Konačno, utvrđena je činjenica da korišćenje ćelija za smeštaj više osoba ima negativan uticaj, na primer, na zdravlje osuđenika, osećaj autonomije i kontakt između osoblja i osuđenika (Paulus, McCain, \& Cox, 1985; Gaes, 1994).

U kojoj meri adekvatni zatvorski uslovi, adekvatan tretman prilagođen karakteristikama i potrebama pojedinačnog osuđenika i pozitivna socijalna klima 


\section{Zbormik IKSI, 2-3/2021 - Lj. Ilijić \\ „Zatvorska socijalna klima - pojam, faktori i značaj zatvorske socijalne klime”, (str. 59-76)}

ostvaruju uticaj na ponašanje osuđenika i redukciju recidivizma, najbolje se očituje na primeru „skandinavske izuzetnosti”. Osim jedinstvenog pristupa zatvorskoj kazni, koja se izriče samo kao krajnje sredstvo, skandinavske zemlje odlikuje i visok stepen poštovanja ljudskih prava osuđenika. Zatvori malih kapaciteta sa otvorenim ćelijama (Molleman \& van der Broek, 2014), nastoje da obezbede adekvatan i pojedincu prilagođen tretman, uz saradnju sa lokalnom zajednicom. Humano postupanje, visok stepen zdravstvene zaštite, izuzetni uslovi smeštaja, dovoljan broj stručnog osoblja, i raznovrsni programi tretmana, obrazovanja i stručne obuke, samo su neki od razloga zašto je skandinavski sistem jedinstven, ne samo po uslovima, već i rezultatima koja se ogledaju u opadajućoj stopi recidivizma i kriminaliteta.

Istažujući kvalitet života osuđenika u norveškim zatvorima, Johnsen i saradnici, iako nisu potvrdili postojanje dramatičnih razlika o kvalitetu života osuđenika $u$ Norveškoj, u poređenju sa osuđenicima u drugim razvijenim evropskim zemljama, takođesu analizirali i veličinu zatvora i zaključili da „decentralizovana i manje hijerarhijski usmerena struktura zatvora, sa nekoliko nivoa i manjim brojem zaposlenih, zajedno sa socijalnim aspektima, stvara fleksibilnu i dinamičnu organizaciju” (Johnsen, Granheim \& Helgesen, 2011: 523), a time i bolji nivo kvaliteta života u zatvorima male veličine. Kao što se očekivalo, oni su takođe ukazali na značaj pozitivnih stavova zatvorskih radnika o zatvorskoj socijalnoj klimi i značaja koji pozitivna socijalna klima ima na tretmanski napredak osuđenika (Johnsen et al., 2011: 523).

Do sličnih nalaza došli su i Mastrobuoni i Terlizzese (2014) u kvazieksperimentalnoj studiji u kojoj su recidiviste iz italijanskog zatvora zatvorenog tipa, zbog prenaseljenosti, premestili u zatvor otvorenog tipa - Bollate. Mastrobuoni i Terlizzese (2014) su došli do podatka o smanjenoj stopi recidivizma za 10\% tokom trogodišnjeg praćenja, kod osuđenika koji su bili godinu dana u Bollatu, nasuprot onim koji su ostali u glavnom zatvoru. Smanjenje stope recidivizma bilo je posebno izraženo kod bivših osuđenika koji su izvršili imovinska krivična dela ili dela kojima su pribavili finansijsku dobit i koji su uhapšeni i osuđeni na početku kriminalne karijere. Ova studija se razlikuje od većine drugih eksperimentalnih studija, po tome što autori pripisuju smanjenje recidivizma jedinstvenoj kulturi i uređenju u Bollatu. Zatvor Bollate, opisan je kao jedini zatvor otvorenih ćelija u Italiji, gde osuđenici „doživljavaju okruženje radikalno drugačije od okruženja u drugim zatvorima, gde se mnogo više poštuje dostojanstvo osuđenika i gde oni aktivno učestvuju u nekim aktivnostima“ (Mastrobuoni \& Terlizzese, 2014: 5). U raspravi o osnovnim mehanizmima autori navode da su ponuda za rad i povratak na tržište rada od presudnog značaja, kao što su i „uslovi poštovanja ljudskog dostojanstva, zajedno sa odgovornošću i produktivnom upotrebom vremena (...) faktori koji „pozitivno utiču na ponašanje nakon puštanja na slobodu“ (Mastrobuoni \& Terlizzese, 2014: 6).

U literaturi se mogu naći opisi niza inicijativa koje su osmišljene u cilju poboljšanja socijalne klime u zatvorima. Na primer, kao odgovor na istraživanje koje sugeriše da neke boje mogu da deluju umirujuće od drugih, zatvor u okrugu Dallas je zidove zatvora obojio u ružičasto u pokušaju da poboljša zatvorsko okruženje (Borghese, 2006). Druge institucije su uvele kućne ljubimce (poput štenaca i ptica) kako bi ove životinje pomogle osuđenicima da nauče osnovne socijalne veštine (Britton, Button, 


\section{Zbormik IKSI, 2-3/2021 - Lj. Ilijić \\ „Zatvorska socijalna klima - pojam, faktori i značaj zatvorske socijalne klime”, (str. 59-76)}

2006; Lindemuth, 2007). Većina ovih eksperimenata, međutim, nije bila predmet formalne evaluacije, pa se zbog toga ne mogu donositi zaključci o njihovoj efikasnosti. Pojedini zatvori, pokušali su uticati na socijalnu klimu angažovanjem većeg broja stručnih radnika koji su „fokusirani na tretman“ (Day et al., 2011). Waters i Megathlin (2002) utvrdili su značajnim poboljšanja u percepciji osuđenika o zatvorskoj socijalnoj klimi 22 meseca nakon zapošljavanja većeg broja stručnih rehabilitacionih radnika.

\section{UMESTO ZAKLJUČKA}

Zatvorska socijalna klima je multidimezionalna i promenljiva kategorija koju oblikuju pojedinci u instituciji, njihove lične, penološke, kriminološke i sociološke karakteristike (Sparks, Bottom \& Hay, 1996). Brojni autori u raspravama o zatvorskoj socijalnoj klimi, ističu značaj odnosa osoblja sa zatvorenicima, kao važnog faktora efikasnog upravljanja zatvorskom zajednicom koji determiniše socijalnu klimu. Operacionalizacija socijalne klime u ovom radu, identifikuje bezbednost, terapijsku podršku i sigurnost kao ključne moderatore pozitivnih tretmanskih ishoda. Modeli promene ponašanja koji su eksplicitni u modelima terapijske zajednice za rehabilitaciju prestupnika sugerišu da je najkorisnija dosledna i podržavajuća povratna informacija osuđenika i stručnog osoblja o problematičnom ponašanju.

Faktori socijalne okoline nesumnjivo igraju važnu ulogu u oblikovanju ponašanja, a zatvorsko socijalno okruženje jedan je od centralnih faktora koji osigurava da se postignute pozitivne promene $u$ ponašanju održavaju i generališu. Pored toga, poboljšana socijalna klima u institucijama može, u kontekstu osuđenika osigurati aktivnije uključivanje u tretmanske sadržaje i ostvarivanje većeg nivoa pozitivnih promena u ponašanju, dok sa aspekta stručnih radnika ona može povećati dobrobit osoblja i njihovu posvećenost poslu, smanjiti dane odsustva i smanjiti disciplinska pitanja sa osobljem, sigurnost ustanove i prekovremeni rad, kao i veću fluktuaciju radnih mesta (Day et al., 2011; Tewksbury \& Higgins, 2006).

Kako bi osigurale što pozitivniju i produktivniju zatvorsku socijalnu klimu, zatvorske uprave treba da razmotre sprovođenje promena na društvenom nivou, ali i na nivou arhitektonskog dizajna zatvora, kako bi povećale svoje kapacitete za rehabilitaciju osuđenika i poboljšale odzivosuđenika za terapijske sadržaje i programe.

\section{LITERATURA}

(1) Ajdukovic, D. (1990). Psychosocial climate in correctional institutions: Which attributes describe it? Environment and Behavior, 22(3), 420-432. https://doi.org/10.1177/0013916590223006

(2) Allen, R. (2017). Roadmap for the Development of Prison-based Rehabilitation Programmes (Vienna: United Nations Office on Drugs and Crime). Available on: https://www.unodc.org/documents/middleeastandnorthafrica/2018/Roadmap_for _the_Development_of_Prison-based_Rehabilitation_Programmes_ENG.pdf (pristup: 17.5.2021.) 


\author{
Zbormik IKSI, 2-3/2021 - Lj. Ilijić \\ „Zatvorska socijalna klima - pojam, faktori i značaj zatvorske socijalne klime”, (str. 59-76)
}

(3) Attar-Schwartz, S. (2017). Experiences of victimization by peers and staff in residential care for children at risk in Israel from an ecological perspective. In: A. V. Rus, S. R. Parris, \& E. Stativa (Eds.), Child maltreatment in residential care (pp. 269-299). Cham: Springer International Publishing AG.

http://dx.doi.org/10.1007/978-3-319-57990-0_13

(4) Auty, K. M., \& Liebling, A. (2019). Exploring the Relationship between Prison Social Climate and Reoffending. Justice Quarterly, 37(2), 358-381.

http://dx.doi.org/10.108o/o7418825.2018.1538421

(5) Beazley, P., \& Gudjonsson, G. (2011). Motivating inpatients to engage with treatment: The role of depression and ward atmosphere. Nordic Journal of Psychiatry, 65(2), 95-100. http://dx.doi.org/10.3109/08039488.2010.502244

(6) Beech, A. R., \& Hamilton-Giachritsis, C. E. (2005). Relationship between therapeutic climate and treatment outcome in group-based sexual offender treatment programs. Sexual Abuse: A Journal of Research and Treatment, 17(2), 127-140. http://dx.doi.org/10.1177/107906320501700204

(7) Beijersbergen, K. A., Dirkzwager, A. J., Eichelsheim, V. I., Van der Laan, P. H., \& Nieuwbeerta, P. (2015). Procedural justice, anger, and prisoners' misconduct: A longitudinal study. Criminal Justice and Behavior, 42(2), 196-218. http://dx.doi.org/10.1177/0093854814550710

(8) Boin, A., \& Rattray, W. A. R. (2004). Understanding prison riots: towards a threshold theory. Punishment and Society, 6(1), 47-65. http://dx.doi.org/10.1177/1462474504039091

(9) Boone, M., Althoff, M., \& Koenraadt, F. (2016). Het leefklimaat in justitiële inrichtingen (Prison Climate in Judicial Institutions). Den Haag, The Netherlands: Boom Juridisch.

(10) Borghese, M. (2006). Prison paints the walls pink after inmates riot. NC Buy website. Available on: http://www.ncbuy.com/news/20061109/o-prison-paintswalls-pink-after.html (pristup: 29.5.2021.)

(11) Bosma, A. Q., van Ginneken, E. F. J., Sentse, M., \& Palmen, H. (2020). Examining Prisoner Misconduct: A multilevel test using Personal Characteristics, Prison Climate and Prison Environmnet. Crime \& Delinquency, 66(4), 451-484. http://dx.doi.org/10.1177/0011128719877347

(12) Bottoms, A. E. (1999). Interpersonal Violence and Social order in Prisons. Crime and Justice, 26, 205-281. http://dx.doi.org/10.1086/449298

(13) Bressington, D., Stewart, B., Beer, D., \& MacInnes, D. (2011). Levels of service user satisfaction in secure settings- A survey of the association between perceived social climate, perceived therapeutic relationship and satisfaction with forensic services. International Journal of Nursing Studies, 48(11), 1349-1356.

https://doi.org/10.1016/j.ijnurstu.2011.05.011

(14) Britton, D. M., \& Button, A. (2006). Prison pups: Assessing the effects of dog training programs in correctional facilities. Journal of Family Social Work, 9(4), 79-95. http://dx.doi.org/10.1300/Jo39vo9no4_o6

(15) Brunt, D., \& Rask, M. (2012). A suggested revision of the community oriented program environmental scale (COPES) for measuring the psychosocial environment of supported housing facilities for persons with psychiatric disabilities. Issues in Mental Health Nursing, 33(1), 24-31. http://dx.doi.org/10.3109/01612840.2011.618237

(16) Camp, S. D., Gaes, G. G., Langan, N. P., \& Saylor, W. G. (2003). The influence of prisons on inmate misconduct: A multilevel investigation. Justice Quarterly, 2O(3), 501-533. http://dx.doi.org/10.1080/07418820300095601 


\author{
Zbormik IKSI, 2-3/2021 - Lj. Ilijić \\ „Zatvorska socijalna klima - pojam, faktori i značaj zatvorske socijalne klime”, (str. 59-76)
}

(17) Casey, S., Day, A., Vess, J., \& Ward, T. (2013). Foundations of offender

rehabilitation. Oxfordshire: Routledge. http://dx.doi.org/10.4324/9780203126813

(18) Cheeseman, K. A., Kim, B., Lambert, E. G., \& Hogan, N. L. (2011). Correctional officer perceptions of inmates and overall job satisfaction. Journal of Crime and Justice, 34(2), 81-102. http://dx.doi.org/10.1080/0735648X.2011.580515

(19) Cooke, D. J. (1992). Prison Violence: A Scottish Perspective. Forum on Corrections Research, 4(3), 23-30.

(20) Crewe, B., Warr, J., Bennett, P., \& Smith, A. (2013). The emotional geography of prison life. Theoretical Criminology, 18(1), 1-19. http://dx.doi.org/10.1177/1362480613497778

(21) Day, A., Casey, S., Vess, J., \& Huisy, G. (2011). Assessing the social climate of Australian prisons. Trends \& Issues in Crime and Criminal Justice, No. 427. Canberra: Australian Institute of Criminology.

(22) Dowden, C., \& Tellier, C. (2004). Predicting work-related stress in correctional officers: A meta-analysis. Journal of Criminal Justice, 32(1), 31-47. http://dx.doi.org/10.1016/j.jcrimjus.2003.10.003

(23) Eichenthal, D. R., \& Jacobs, J. B. (1991). Enforcing the Criminal Law in State Prisons. Justice Quarterly, 8(3), 283-303. http://dx.doi.org/10.1080/07418829100091061

(24) Gadon, L., Johnston, L., \& Cooke, D. (2006). Situational variables and institutional violence: A systematic review of the literature. Clinical Psychology Review, 26(5), 515-534. https://doi.org/10.1016/j.cpr.2006.02.002

(25) Gaes, G. G. (1994). Prison Crowding Research Reexamined. Federal Bureau of Prisons, Washington, D.C. http://dx.doi.org/10.1177/0032855594074003004

(26) Garland, D. (1990). Punishment and Modern Society: A Study in Social Theory. University of Chicago Press, Chicago.

http://dx.doi.org/10.7208/chicago/9780226922508.001.0001

(27) Garrett, D. K., \& McDaniel, A. M. (2001). A new look at nurse burnout: The effects of environmental uncertainty and social climate. The Journal of Nursing Administration, 31(2), 91-96. https://doi.org/10.1097/00005110-200102000-00009

(28) Griffin, M. L. (1999). The Influence of Organizational Climate on Detention Officers' Readiness to Use Force in a County Jail. Criminal Justice Review, 24(1), 1-24 https://doi.org/10.1177/073401689902400102

(29) Griffin, M. L., Hogan, N. L., Lambert, E. G., Tucker-Gail, K. A., \& Baker, D. N. (2010). Job involvement, job stress, job satisfaction, and organizational commitment and the burnout of correctional staff. Criminal Justice and Behavior, 37(2), 239-255. https://doi.org/10.1177/0093854809351682

(30) Hall, P., \& Chong, M. D. (2018). A prison's social climate, and its impact on reintegration and recidivism. James Cook University Law Review, 24, 231-242.

(31) Härenstam, A., Palm, U. P., \& Theorell, T. (1988). Stress, health and the working environment of Swedish prison staff. Work and Stress, 2(4), 281-290. https://doi.org/10.1080/02678378808257489

(32) Harer, M. D., \& Steffensmeier, D. J. (1996). Race and Prison Violence. Criminology, 34(3), 323-355. https://doi.org/10.1007/s10610-011-9158-7

(33) Hughes, E. (2009). Thinking inside the box: Prisoner education, learning identities, and the possibilities of change. In B. M. Veysey, Christian, J., \& Martinez, D. J. (Eds.), How offenders transform their lives (pp. 100-116). Cullompton, Devon: Willan Publishing.

(34) Jiang, S., \& Winfree, L. T., Jr. (2006). Social support, gender, and inmate adjustment to prison life: Insights from a national sample. The Prison Journal, 86(1), 32-55. https://doi.org/10.1177/0032885505283876 


\author{
Zbormik IKSI, 2-3/2021 - Lj. Ilijić \\ „Zatvorska socijalna klima - pojam, faktori i značaj zatvorske socijalne klime”, (str. 59-76)
}

（35） Johnsen, B., Granheim, P. K., Helgesen, J. H. I. (2011). Exceptional Prison Conditions and the Quality of Prison Life: Prison Size and Prison Culture in Norwegian Closed Prisons. European Journal of Criminology, 8(6), 515-529. http://dx.doi.org/10.1177/1477370811413819

(36) Johnston, N. (2000). Forms of Constraint. A History of Prison Architecture. University of Illinois Press, Champaign.

(37) Lahm, K. F. (2008). Inmate-on-inmate assault: A multilevel examination of prisonviolence. Criminal Justice and Behavior, 35(1), 120-137. https://doi.org/10.1177/0093854807308730

(38) Liebling, A. (2011). Distinctions and Distinctiveness in the Work of Prison Officers: Legitimacy and Authority Revisited. European Journal of Criminology, 8(6), 484499. https://doi.org/10.1177/1477370811413807

(39) Liebling, A., assisted by Arnold, H. (2004). Prisons and their moral performance: A study of values, quality and prison life. Oxford: Oxford University Press.

(40) Lindemuth, A. L. (2007). Designing therapeutic environments for inmates and prison staff in the United States: Precedents and contemporary applications. Journal of Mediterranean Ecology, 8(1), 87-97.

(41) Long, C. G., Anagnostakis, K., Fox, E., Silaule, P., Somers, J., West, R., \& Webster, A. (2011). Social climate along the pathway of care in women's secure mental health service: Variation with level of security, patient motivation, therapeutic alliance and level of disturbance. Criminal Behaviour and Mental Health, 21(3), 202-214. http://dx.doi.org/10.1002/cbm.791

(42) Lösel, F. (1995). Increasing consensus in the evaluation of offender rehabilitation? Lessons from recent research syntheses. Psychology, Crime \& Law, 2(1), 19-39. http://dx.doi.org/10.1080/10683169508409762

(43) Maruna, S. (2010). The great escape: Exploring the rehabilitative dynamics involved in 'Changing Tunes'. Retrieved from Changing Tunes. http://www.changingtunes.org.

(44) Maschi, T., Viola, D., Morgen, K., \& Koskinen, L. (2015). Trauma, stress, grief, loss, and separation among older adults in prison: The protective role of coping resources on physical and mental well-being. Journal of Crime and Justice, 38(1), 113-136. http://dx.doi.org/10.1080/0735648X.2013.808853

(45) Mastrobuoni, G., \& Terlizzese, D. (2014). Rehabilitating Rehabilitation: Prison Conditions and Recidivsm. Einaudi Institute for Economic and Finance (EIEF) - Working paper 13/14

(46) Michie, S., \& Williams, S. (2003). Reducing work related psychological ill health and sickness absence: A systematic literature review. Occupational and Environmental Medicine, 6o(1), 3-9. http://dx.doi.org/10.1136/oem.60.1.3

(47) Molleman, T., \& Leeuw, F. L. (2012). The influence of staff on prison conditions of inmates: a multilevel approach. European Journal of Criminal Policy and Research, 18(2), 217-233.

(48) Molleman, T. C., \& van der Broek (2014). Understanding the links between perceived prison conditions and prison staff. International Journal of Law, Crime and Justice, 42(1), 33-53. http://dx.doi.org/10.1016/j.ijlcj.2014.01.001

(49) Moos, R. H. (1974). Evaluating treatment environments: A social ecological approach. New York, NY: John Wiley

(50) Moos, R. H. (1975). Evaluating Correctional and Community settings. New York, NY: Wiley

(51) Moos, R. H. (1989). Ward Atmosphere Scale manual (2nd ed.). Palo Alto, CA: Consulting Psychologists Press.

(52) Moos, R. H. (2003). The social climate scales: A user's guide. Redwood City, CA: Mind Garden Inc. 


\author{
Zbormik IKSI, 2-3/2021 - Lj. Ilijić \\ „Zatvorska socijalna klima - pojam, faktori i značaj zatvorske socijalne klime”, (str. 59-76)
}

(53) Morgan, R. (1994). Minimising the risk of suicide in custody. In: Liebling, A., \& Ward, T. (eds.), Deaths in custody: International perspectives. London: Institute for the Study and Treatment of Delinquency.

(54) Ortmann, R. (2000). The effectiveness of social therapy in prison - A randomized experiment. Crime and Delinquency, 46(2), 214-232. http://dx.doi.org/10.1177/0011128700046002005

(55) Parker, C. P., Baltes, B. B., Young, S. A., Huff, J.W., Altmann, R. A., LaCost, H. A., \& Roberts, J. E. (2003). Relationships between psychological climate perceptions and work outcomes: A meta-analytic review. Journal of Organizational Behavior, 24(4), 389-416. http://dx.doi.org/10.1002/job.198

(56) Paulus, P.B., McCain, G., \& Cox, C. (1985). The effects of crowding in Prisons and Jails. In: Farrington, D.P., Gunn, J. (Eds.), Reactions to Crime: The Public, the Police, Courts and Prisons (pp. 113-134). Wiley.

(57) Piirainen, H., Räsänen, K., \& Kivimäki, M. (2003). Organizational climate, perceived work-related symptoms and sickness absence: A population-based survey. Journal of Occupational and Environmental Medicine, 45(2), 175-184. https://doi.org/10.1097/01.jom.0000052957.59271.f4.

(58) Reisig, M. D., \& Mesko, G. (2009). Procedural Justice, Legitimacy, and Prisoner Misconduct. Psychology, Crime \& Law, 15(1),41-59. http://dx.doi.org/10.1080/10683160802089768

(59) Ros, N., van der Helm, P., Wissink, P., Stams, G., \& Schaftenaar, P. (2013). Institutional climate and aggression in a secure psychiatric setting. The Journal of Forensic Psychiatry and Psychology, 24(6), 713-727. http://dx.doi.org/10.1080/14789949.2013.848460

(6o) Ross, M. V., Diamond, P., Liebling, A., \& Saylor, W. (2008). Measurement of prison social climate: A comparison of an inmate measure in England and the US. Punishment \& Society, 10(4), 447-474. http://dx.doi.org/10.1177/1462474508095320

(61) Schalast, N., Redies, M., Collins, M., Stacey, J., \& Howells, K. (2008). EssenCES, a short questionnaire for assessing the social climate of forensic psychiatric wards. Criminal Behaviour and Mental Health, 18(1), 49-58. https://doi.org/10.1002/cbm.677

(62) Schubert, C. A., Mulvey, E. P., Loughran, T. A., \& Loyosa, S. H. (2012). Perceptions of institutional experience and community outcomes for serious adolescent offenders. Criminal Justice and Behavior, 39(1), 71-93. https://doi.org/10.1177/0093854811426710

(63) Snacken, S. (2010). Resisting punitiveness in Europe? Theoretical Criminology, 14(3), 273-292. https://doi.org/10.1177/1362480610370165

(64) Sparks, R. Bottoms, A. E., \& Hay, W. (1996). Prisons and the problem of order. Oxford, England: Oxford University Press. http://dx.doi.org/10.1093/acprof:oso/9780198258186.001.0001

(65) Specter, D. (2006). Making prisons safe: strategies for reducing violence. Washington University Journal of Law \& Policy, 22, 125-134.

(66) Steinke, P. (1991). Using Situational Factors to predict types of Prison Violence. Journal of Offender Rehabilitation, 17(1-2), 119-132. http://dx.doi.org/10.1300/Jo76v17no1_09

(67) Tewksbury, R., \& Higgins, G. E. (2006). Prison staff and work stress: the role of organizational and emotional influences. American Journal of Criminal Justice, 3O(2), 247-269. http://dx.doi.org/10.1007/BFo2885894

(68) Tonkin, M. (2015). A Review of Questionnaire Measures for Assessing the Social Climate in Prisons and Forensic Psychiatric Hospitals. International Journal of 
Offender therapy and Comparative Criminology, 6o(12), 1376-1405. https://doi.org/10.1177/0306624X15578834

(69) Ulrich, C., O'Donnell, P., Taylor, C., Farrar, A., Danis, M., \& Grady, C. (2007). Ethical climate, ethics stress, and the job satisfaction of nurses and social workers in the United States. Social Science and Medicine, 65(8), 1708-1719. http://dx.doi.org/10.1016/j.socscimed.2007.05.050

(70) van der Helm, P., Beunk, L., Stams, G. J., \& van der Laan, P. (2014). The relationship between detention length, living group climate, coping and treatment motivation among juvenile delinquents in a youth correctional facility. The Prison Journal, 94(2), 260-275.

(71) Van Zyl Smit, D., \& Snacken, S. (2009). Principles of European prison law and policy: Penology and human rights. Oxford, UK: Oxford University Press.

(72) Waller, E. (2000). Disjunction and integration in prison education. In: D. Wilson, \& A. Ruess, (Eds.) Prisoner(er) education: Stories of change and transformation (pp. 106-137). Winchester: Waterside Press.

(73) Waters, J. E. (1999). The impact of work resources on job stress among correctional treatment staff. Journal of Addictions and Offender Counselling, 2O(1), 26-34. http://dx.doi.org/10.1002/j.2161-1874.1999.tbo0138.x

(74) Waters, J. E., \& Megathlin, W. (2002). Evaluating change in social climate in a close security state correctional facility. Journal of Offender Rehabilitation, 34(4), 71-84. http://dx.doi.org/10.1300/Jo76v34no4_04

(75) Wenk, E. A., Moos, R. H. (1972). Social climates in prison: An attempt to conceptualize and measure environmental factors in total institutions. Journal of Research in Crime \& Delinquency, 9(2), 134-148. http://dx.doi.org/10.1177/002242787200900206

(76) Wright, K. N. (1991). The violent and victimized in the male prison. Journal of Offender Rehabilitation, 16(3-4), 1-25. https://doi.org/10.1300/Jo76v16no3_01

(77) Yewkes, Y. (2018). Just design: Healthy Prison and the Architecture of hope. Australian \& New Zealand Journal of Criminology, 51(3), 319-321. https://doi.org/10.1177/0004865818766768 


\section{PRISON SOCIAL CLIMATE The Concept, Factors and Significance of the Prison Social Climate}

The increasingly intensive focus of professional scientific attention on the study of prison social climate in recent decades is extremely important because the research results indicate that prison characteristics (physical, architectural, social, organizational, etc.) mediate between offenders and rehabilitation or therapeutic measures. In other words, the social or institutional climate can potentially facilitate the successful rehabilitation of convicts or hinder their progress. A review of the literature reveals numerous different terminological definitions and definitions of the concept of prison social climate, so it is often defined as the material, social and emotional state of a given unit and involves the interaction between these factors. General conceptualizations of social climate include relational climate, psychosocial environment, social atmosphere, social environment, and classroom atmosphere. The social climate can also be measured by assessing the actual, desirable, and expected social climate and how it is perceived by convicts, prison staff, or individuals from the community. In this paper, the author tries to shed light on the notion of prison social climate, as well as the factors that determine it. Special emphasis is placed on the perception of prison social climate by professionals, the impact that social climate has on the behavior of convicts, as well as consideration of all those aspects that arise from the work environment, type of work organization, and relationships that affect the formation of the social climate in a prison environment.

KEY WORDS: prison social climate / prison environment / convict behavior / the role of professional staff 